\title{
SONATA PARA DOS ACTORES ${ }^{1}$
}

\section{Eduardo Contreras Soto}

\author{
A Tizoc Arroyo y Óscar Ulises Cancino
}

\section{I \\ Alegre asaz.}

UNO. Tengo frío.

Estoy descobijado, tal vez perdí al sol cuando miraba mi sombra y el negro que miré me trajo a este blanco helado y tengo frío.

DOS. Ardo.

Adentro de mí siento crecer algo rojo que sube por mis grises y me inunda de flamas, como noche de verano sin lluvia.

Ardo.

UNO. Moverme me calentaría, pero no quiero...

No sé si deba moverme y ganar calor, no sé por qué esta onda helada me tiene quieto, inmóvil.

DOS. No puedo estarme quieto.

La paz sería la muerte, el rojo es mi energía y es mi combustible

${ }^{1}$ Estrenada el 9 de febrero de 2004 por Enrique Durán y Roberto Manzano, en una producción del grupo Movimiento Escénico bajo la dirección de Juan Manuel Martínez, en el Foro Antonio López Mancera de la Escuela Nacional de Arte Teatral del INBA. México, D.F., Centro Nacional de las Artes. 
y deseo, deseo moverme, tengo el deseo del desierto y el del trópico.

Este calor me seca, me baña de sudor.

Quisiera el agua para refrescarme, quisiera el viento para secar este fluir.

UNO. Este viento me paraliza.

Si tan sólo fuera menos viento

o menos frío, entonces yo andaría por estos blancos con más color y más calor que el negro de mi sombra, y el blanco se desdoblaría en los colores de la selva, o en el brillo del sol que no puedo mirar de tan blanco, y ahí está el brillo, ahí está el brillo, pero no está el sol, no está el calor.

Dos. Si hubiera luna, luna llena, entonces habría fresco frío frígido; pero no hay luna, hay luna nueva, negra sin fulgor la noche, hay negro que me asfixia en más calor, hay mis deseos que crecen y se acumulan y no me dejan desatar el rojo en fríos blancos de la luna llena.

Quiero blanco de hielo, blanco de nieve, blanca blancura de una sal que apague el fervor de esta fiebre roja.

UNO. Quiero un cálido blanco.

DOS. Quiero un blanco lunar.

UNO. ¿Quiero un cálido blanco? 
DOS. ¡Quiero un blanco lunar!

UNO. ¿Qué quiero, que me da no sé qué frío?

DOS. ¿Qué blanco, qué frío, qué quieres?

(Se repite todo el diálogo anterior una vez,

hasta regresar a este punto; de aqui se continúa:)

UNO. ¿Qué quieres?

DOS.

¿Yo qué quiero?

UNO. Yo no sé qué quiero.

DOS. Ardo en deseos.

UNO.

Me es indiferente.

DOS. Busco el blanco frío.

UNO. Veo el blanco brillo.

DOS. Sufro el negro sofoco, la fiebre roja.

UNO. Mi sombra es negra, mi negro es frío.

DOS. Frío firme, fuerte frío, fresco frío, quiero salir del ardor en que me frío.

UNO. Que fresca fuerza tengo, y no sé qué ardor traes contigo, que el blanco de mi frío se me encarna con tu rojo, y estoy pasando de mi frío a tu calor, estoy entrando del frío.

DOS. Ardo y deseo y me llama tu blanco porque es negro, me llena de luna nueva que al fin es llena, esta nueva luna que negra me ardía en su oscuro sofoco y llena me refresca, me baña de blanco.

UNO. Tu rojo es blanco y arde, y traes contigo todos los colores que han desdoblado todos tus calores y el frío viaja, ya se va a tu lado, y no sé qué me pasa con tu fiebre. 
DOS. Me siento fresco, fuerte, firme, me han hecho blanco tus negrores, me recupero de mis fiebres, gozo como el gozar de una lluvia sobre el río entre mil verdes, vibro como el vibrar ante la sacudida del viento que traen los polos blancos, y me muevo y me muevo frío, y el ardor me movía y me dejaba inquieto, y ahora me sacudo y me deslizo en este blanco y necesito el movimiento, me mueve el viento, me mueve el agua, me mueve el hielo, me mueve el blanco, me mueve el negro.

UNO. ¿A dónde vas?

DOS.

Me voy,

crezco, lleno, menguo, nuevo, crezco, lleno, menguo, nuevo, y así me voy, blanco, rojo, negro, rojo, blanco.

UNO. Ardo,

me dejas rojo, me dejas encarnado, me dejas los colores del calor, me dejas los calores del color. ¿Qué voy, a dónde hago?

Dos. No sé que hago, no sé qué quiero; me enfría el fresco firme, fuerte, tengo más blanco y negro, menos rojo, tengo frío.

UNO. Ardo.

DOS. Tengo frío.

UNO. Ardo.

DOS. Tengo frío, 


\section{II}

\section{Lento}

UNO. Hace días que pienso, que reflexiono, que analizo, que quiero explicaciones, que explico y que razono, y para todo puede haber por qué.

DOS. Ayer sentí algo, algo aquí. Aquí he sentido lo más hondo y no tengo por qué sentirlo, pero lo sentí.

Quisiera saber si lo siento de verdad, o si no es más que un sueño.

Pero lo sentí, lo he sentido, y ya lo siento, ya lo siento.

UNO. ¿Qué sientes?

DOS. Yo qué sé.

UNO. ¿Por qué lo sientes?

DOS. Porque sí. ¿Pues tú qué piensas?

UNO. Que alguna razón habrías de tener para sentir eso que sientes.

DOS. ¿Siento?

UNO. Tú lo has dicho: sientes.

DOS. ¿Tú qué piensas?

UNO. En que sientes lo que sientes, y que debes de sentir, y qué debes de sentir.

DOS. Yo no sé qué siento.

UNO. Yo te diré lo que pienso.

Lo que sientes, deberías de sentirlo, por alguna razón, por una causa, porque el sentir no puede ser así, sin motivo ninguno. 
Tú has llegado a sentir, $\mathrm{y}$ algo te tuvo que llevar al sentimiento.

¿Qué será lo que sientes?

¿Será algo alegre, triste, noble, ruin?

¿Será un sentir de gozo y de volar

de nubes rojas en la tarde fría, un terminar el día en santa calma y en rico despilfarro de pobreza, que alegre tus escasos preocupares y aumente la fortuna de tus bienes?

DOS. ¿Y tengo que saber si lo que siento es algo alegre, triste, noble, ruin?

UNO. ¿Y no podría ser que sientes el rumor de la lluvia que recorre las tierras secas de tus cosechares, como caer de temporal que pasa y no regresa hasta el año siguiente?

DOS. ¿Y tienes que medir con tus pensares si lo que siento es como piensas?

Yo sólo sé que siento,

y no siento que deba de saber por qué.

UNO. Es que no piensas lo que ha de sentirse,

lo que se siente porque así sería,

porque el sentir es cosa de pensarse

si no sabes sentir.

DOS. ¿Y tú sabes sentir?

UNO.

Yo sé qué siento.

DOS. Y tú que sabes, ¿tú qué sientes?

UNO.

¿Yo qué siento?

DOS. ¿Tú qué sientes?

UNO.

Siento...

DOS.

Sientes...

UNO. Pienso que yo siento alguna cosa- 
DOS. ¿¿Piensas?!

¿Pero tú qué sientes?

UNO. Es que si lo pienso, no sé lo que siento...

Siento... Siento... que siento...

Dos. Si no sabes sentir, tú dices que el sentir es cosa de pensarse. Tú no sabes sentir.

UNO. Hay que pensar en qué se siente.

DOS. Nunca he sentido eso que piensas.

UNO. Tiene que haber por qué sentir.

No hay ahora sin su antes, para un por qué tiene que haber un porque.

$\mathrm{Tu}$ sentir me ha puesto a pensar, y de algún antes vino lo que sientes.

Si pudiera saber cómo es eso que sientes, si pudiera tener una idea precisa de eso.

Si poseyera yo esa idea, si la pudiera definir, delimitar, medirla, si pudiera llevar tu sensación, tu sentimiento, al pensar que me pide algún motivo, alguna forma de enraizar esa razón...

DOS. Yo siento esto que siento, y ayer también sentí lo mismo, y tal vez lo que ahora siento ya no es el sentir de ayer, yo no sé nada; sólo siento, y si me dedicara al pensamiento de explicar estos sentires, no sé lo que sentiría, y es que al sentir de nuevo, siento más, y sólo sé que este sentir me abarca por el ojo y su nervio y este brazo 
y ahora que más siento, me siento lleno de otra sensación que va de pierna en pierna y sube y baja por mi adentro, y entonces sé que aún me abarca y más y más abarca y cubre más.

En fin, que ya que siento, yo no mido, que cuando mido el sentimiento el brazo ya no siente, y esta pierna no lleva nada a la otra pierna, y ya no siento que este ojo me siente y algo sale de mí, que ya no siento lo que sale y lo que queda. Siento... Pues siento y ya.

UNO. ¿Por qué todo es sentir?

DOS. ¿Por qué todo es pensar?

UNO. Yo no sé qué decirte.

DOS. Yo tampoco.

(Pausa.)

UNO. ¿Tú qué sientes?

DOS. ¿Tú qué piensas?

UNO. Si pudiera sentir...

DOS. Si pudiera pensar...

UNO. Tendrías nubes rojas en tu tarde fría y caer de temporal en tierra seca.

DOS. Pienso que así sería.

UNO. Siento que así podría ser. 


\section{III \\ Alegrillo muy sostenido}

UNO. ¿Adónde estás?

DOS. Estoy acá.

UNO. ¿Adónde acá?

DOS. Aquí, donde me ves.

UNO. Yo no te veo.

DOS. Estoy aquí, ya puedes verme.

¿No quieres encontrarme?

Me estás buscando por sitios

en donde antes me hallabas,

me buscas allí donde una vez estuve,

pero ya no he regresado allá.

Me buscas en tu mapa, en tus cuadrantes,

en tus coordenadas,

pero yo estoy en otra parte,

estoy cerca de ti, pero no donde buscas, estoy junto a ti mismo, cerca y junto, y no me buscas donde yo deseo estar.

Aquí me tienes, heme aquí:

mira que sigo aquí, aunque no me mires.

UNO. No te hallo, no te encuentro.

Te escucho, estás muy cerca, aquí te tengo, pero cuando te quiero ver, ya no te encuentro.

Me siento solo y aquí estás conmigo, adonde avanzo siento que tú avanzas.

Pero no te hallo, ya no doy contigo,

no sé si vamos por la misma ruta,

porque te sigo y tú me sigues,

pero no puedo verte. ¿Dónde estás?

DOS. Tú quieres que yo esté donde tú quieres, tu crees que sólo puedo estar donde tú crees, pero aquí estoy contigo donde quiero, 
y si tú quieres, me verás contigo.

Pon algo de ti mismo, pon un poco

de buena voluntad para encontrarnos.

Deja un poco de tanto que tú quieres para ti,

deja que haya un poco para estar,

deja ser libre lo que tienes cerca y junto.

Aquí estoy.

UNO. Eres tú.

DOS. Yo soy.

UNO. Qué raro. Yo te había visto de otro modo.

Dos. Por eso no me hallabas. Aquí estoy.

UNO. Tenía que salir de mí un poquito, para llegar a ver adónde estabas.

DOS. Ahora podemos regresar a tu lugar.

UNO. No. Vamos a otra parte.

DOS. ¿Adónde?

UNO. Adonde quieras.

DOS. No. Donde tú quieras.

UNO.

No.

DOS. No quieres volver a encerrarte para no volver a perderme.

UNO. Sí.

DOS. Vayamos juntos, a ver dónde.

UNO. Vamos.

DOS. ¿No sientes el aroma rojo, intensamente rojo de esos zafiros y el rubí?

UNO. Perdón, pero me había distraído con la dureza y los destellos tensos de aquellos pétalos de azalea.

DOS. Pero yo ahora huelo esta obsidiana como quien descubriera un expediente.

UNO. Tal vez debas sentir estas facetas del duro perfilar entre las vetas que en bruto dan todas mis azucenas. 
DOS. Y ven a contemplar cómo hay perfumes con los que se disipan los disgustos, como el de mi cerámica esmeralda y mi ágata de esmalte embriagador.

UNO. A mí lo que me tiene encandilado es el cambiar de luces semafóricas del reflejante azahar que trae clavel.

DOS. Perfumes.

UNO. Relumbrares.

DOS. Oler gozos y ampliares.

UNO. Durar con duras tallas.

DOS. El brillo de esta esencia.

UNO. La esencia de este brillo.

DOS. Si pudieras venir a donde nada el aire...

UNO. Aquí puedo esperarte de tu viaje...

DOS. ¿Adónde estás?

UNO. Estoy acá.

DOS. ¿Adónde acá?

$$
\text { UNO. Aquí, donde me ves. }
$$

Dos. Yo no te veo.

UNO.

Estoy aquí, ya puedes verme.

¿No quieres encontrarme?

Me estás buscando por sitios

en donde antes me hallabas, me buscas allí donde una vez estuve, pero ya no he regresado allá.

Me buscas en tu mapa, en tus cuadrantes, en tus coordenadas, pero yo estoy en otra parte, estoy cerca de ti, pero no donde buscas, estoy junto a ti mismo, cerca y junto, y no me buscas donde yo deseo estar. Aquí me tienes, heme aquí: mira que sigo aquí, aunque no me mires. 
DOS. No te hallo, no te encuentro.

Te escucho, estás muy cerca, aquí te tengo, pero cuando te quiero ver, ya no te encuentro.

Me siento solo y aquí estás conmigo, adonde avanzo siento que tú avanzas.

Pero no te hallo, ya no doy contigo, no sé si vamos por la misma ruta, porque te sigo y tú me sigues, pero no puedo verte. ¿Dónde estás?

UNO. Tú quieres que yo esté donde tú quieres, tu crees que sólo puedo estar donde tú crees, pero aquí estoy contigo donde quiero, y si tú quieres, me verás contigo. Pon algo de ti mismo, pon un poco de buena voluntad para encontrarnos. Deja un poco de tanto que tú quieres para ti, deja que haya un poco para estar, deja ser libre lo que tienes cerca y junto. Aquí estoy.

DOS. Eres tú.

UNO. Yo soy.

DOS. Qué raro. Yo te había visto de otro modo.

UNO. Por eso no me hallabas. Aquí estoy.

Dos. Tenía que salir de mí un poquito, para llegar a ver adónde estabas.

UNO. Ahora podemos regresar a tu lugar.

DOS. No. Vamos a otra parte.

UNO. ¿Adónde?

DOS. Adonde quieras.

UNO. No. Donde tú quieras.

DOS. No.

UNO. No quieres volver a encerrarte para no volver a perderme.

DOS. Sí.

UNO. Vayamos juntos, a ver dónde. DOS. Vamos. 


\section{IV \\ Andante acelerando}

UNO. Hace algún tiempo yo tenía frío o bien yo ardía, y me daba por ponerme a pensar y luego me llegaba un sentimiento, y emprendía unas búsquedas en las que a nadie hallaba, hasta que al fin podía ver a quien buscaba, y entonces yo era muy feliz y acompañado y amaba el color verde de las flores y el perfume del jade.

Entonces yo soñaba...

Pero yo ya no sueño. Ya no ocurre.

Hola.

DOS. Sí, ¿qué pasó?

UNO. ¿Cómo estás?

Bien. O bueno, eso creía.

UNO. Te quiero.

DOS.

Ya lo sé.

UNO.

Tú no me quieres.

DOS. No a tu manera.

UNO.

Como yo te quiero,

es como soñaba quererte, era algo bueno aquel quererte que entonces yo soñaba. Pero yo ya no sueño. Ya no ocurre.

DOS. Yo sueño.

Yo sueño hermoso y capturable y digno de guardar en disco duro cuando tengo un con quién y en qué soñar. Pero no llego aún a esa edad en que se sueña, como sueñan los que saben de adentro. 
Tú dime cómo sueñas;

tú has soñado como yo quisiera.

UNO. Ésos sí que eran sueños: en los años

de entonces yo soñaba.

Pero yo ya no sueño. Ya no ocurre.

Dos. No es cierto. No es posible.

El día que dejaras de soñar

no habría nadie que te amara.

UNO. Pues ya fui amado. El sol acarició mi faz.

Y ya no sueño. Aquello ya pasó.

Dos. Sueña conmigo; sueña por mí.

UNO. No puedo, aunque quisiera. Ya no ocurre.

DOS. Todo llega a destiempo.

UNO.

Todo acaba.

(Pausa.)

DOS. Pues yo quiero soñar, y he de soñar.

Será un tratar y un reto,

será lo que soñare,

y yo he de arder y he de ser rojo,

y lucharé con mis células,

mis nos, mis todavías,

mis hambres, mis pedazos;

y esas piedras me dirán sus aromas,

y encontraré el cristal que hay en mis flores,

y sentiré cuanto haya que pensar

y buscaré todo lo que no pueda hallarse.

UNO. Buen viaje.

DOS. Ven conmigo.

UNO. ¿Por?

DOS. Tú ven, y luego ya será lo que hubiere de ser.

UNO. Tú quieres que yo vuelva al día

cuando flotaba y era vuelo, 
y podía dormir en un desvelo,

o entonces yo soñaba.

Pero yo ya no sueño. Ya no ocurre.

Dos. No lo has vuelto a intentar.

UNO. Ya no veo para qué.

DOS. Porque yo estoy aquí.

UNO. Tú sueña. Vuela. Flota.

Nada. Sube. Armoniza.

Escala. Logra. Insiste.

Lucha. Vibra. Revuelve.

DOS. Tú sabes cómo. Dime.

Ayúdame a caminar el camino, como alimento para mis soñares, que los sueños con pan son buenos.

UNO. Aquello era gustoso alimento;

pues bastaba soñar para mis hambres, si entonces yo soñaba.

Pero yo ya no sueño. Ya no ocurre.

DOS.

Mira,

aquí no hay luz. Aquí yo digo que la sombra es un sueño, y que no existe, y sólo existe lo que yo me sueñe, y aquí habrá luz.

UNO. Y la hay.

DOS. ¿Ya ves cómo se puede?

UNO. Tú puedes. Si tú quieres.

DOS. Ahora mira cómo miro tu mirada, y estoy en ti y estás dentro del iris: tú tienes ese sueño entre tus blancos, el sueño que aprendiste en otro tiempo y que no quieres compartir conmigo.

UNO. Cuando aprendí ese sueño, ya no era novedad lo que aprendía: ya entonces yo soñaba. Pero yo ya no sueño. Ya no ocurre. 
DOS. Que todo puede ser, si serse puede.

¿Ves hacia allá? Mira: nos miran, no dejan de mirarnos.

Son ojos que al mirar, entran en mi iris

y tienen todos los sueños que sueño

y ensueñan blancos de los que me adueño.

Y miran en mis ojos lo que anhelan, y al mirar yo, miro por ellos.

Miren cómo me miran, y ahora miren

como él no quiere que soñemos.

UNO. Yo lo he intentado. Te lo juro.

Yo quise regresar a aquellos fondos

donde nadaba y todo en mí era flote, $\mathrm{y}$ volaban mis pies y mis deseos

y mis cuentas y mis pagos pendientes;

y el agua en mí pasaba y me permeaba

y yo era uno y era todo con el agua,

y el sueño que soñaba lo invadía

todo de a poco, poco que era nada,

hasta que nada y nada era en el agua

mi sueño, mi flotar, mi alma permeada,

y entonces yo soñaba.

Pero yo ya no sueño. Ya no ocurre.

DOS. Verás que yo sí puedo. Yo comienzo.

Ahora quiero la paz y quiero el pan,

y quiero pan con paz y quiero el mundo todo premio,

y fiesta y baile y música y canciones.

Yo sé que con soñarlo basta.

Cierro los ojos y hemos de cerrarlos todos.

Ciérralos tú. Cerremos lo que sea de ver.

Basta el deseo. Cierren. Cierren todo.

Sueñen. Sueñen que paz y pan,

que quiero y que podemos. 
UNO. $\quad$ Y hemos de estar cerrados y no mover nada más que este sueño para que haya tu sueño?

DOS. Basta con la intención. ¿O no? Y ahora, a abrir el iris.

No más ojos cerrados. ¿Y bien?

UNO. Te lo dije. No me deja feliz decir tal frase, pero así ocurre: Ya no ocurre.

Dos. No hay nada... Ni paz, ni pan.

UNO. No hay sueño. Tú no sueñas, yo ya no sueño; ellos ya no sueñan.

DOS. No hay peor ciego que el que no quiere soñar. Insistiré.

UNO. Fracasarás.

DOS. ¿Por qué me enfrías cuando ardo? ¿Por qué ese helado blanco pa mi rojo?

UNO. Sólo una vez soñamos. No se repetirá.

Dos. Ven a intentarlo, inténtalo otra vez, como una vez pudiste.

UNO. Entonces yo soñaba.

Pero yo ya no sueño. Ya no ocurre.

DOS. No te puedes rendir.

UNO. Ya estoy rendido.

DOS. Marchemos y verás.

UNO. Yo ya no sueño.

DOS. Ocurrirá el futuro.

UNO. Ya no ocurre.

DOS. Ven a envolver mi sueño.

UNO.

Yo no voy.

DOS. Sueño.

UNO.

Sueña si quieres. 
DOS. Sueño.

UNO. Sueña si puedes.

DOS. Sueño.

UNO. Sueña si piensas.

DOS. Sueño.

UNO. Sueña si sientes.

DOS. ¡Sueño!

UNO. Dí lo que sueñas.

DOS. ¡Sueño!

UNO. Da lo que sueñas.

DOS. ¡Sueño!

UNO. ¡Ve lo que sueñas!

DOS. ¡ßSueño!!

UNO. ¡Ve a lo que sueñas!

DOS. ¡¡Sueño!!

UNO. ¡iHaz lo que sueñas!!

DOS. ¡ißSueño!!!

UNO. iißrita qué sueñas!!!

(Pausa.)

DOS. No puedo.

UNO. ¿Entonces?

Dos. Yo soñaba.

Pero yo ya no sueño.

UNO. ¿Ya no ocurre?

DOS. Pero puede ocurrir. Debe ocurrir.

Hay algo que aquí siento, algo en lo que he pensado.

Puedo soñar. Debo soñar.

UNO. Mira cómo nos miran.

DOS. Es que quieren soñar, y ya no saben.

UNO. Si piensan y si sienten, si sienten y si piensan, pueden soñar. Deben soñar. 
DOS. ¿La paz y el pan?

UNO. El pan y la paz.

DOS. Hay que insistir.

UNO. Hay que insistir.

DOS. Insistiremos.

UNO. Insistamos.

DOS. Mira: miro. Miren, miremos.

Es aquí, fue más allá.

Siento y pienso, pienso y siento,

Busco y no hallo, ardo y me hielo.

Me voy, nos vamos, hasta aquí llegamos, todo vuelve, todo volverá, la paz y el pan, el sueño.

UNO. Sueño.

DOS. ¡Sueñas!

UNO. Nos iremos soñando.

DOS.

Nos iremos.

$$
* * *
$$

